\title{
Development and characterization of 28 polymorphic EST-SSR markers for Cunninghamia lanceolata (Taxodiaceae) based on transcriptome sequences
}

\author{
By Y. Wen ${ }^{1), 2), *)}$, S. Ueno ${ }^{2)}$, W. HAN ${ }^{1)}$ and Y. TsumurA ${ }^{2)}$
}

(Received $9^{\text {th }}$ November 2012)

\begin{abstract}
The Chinese fir (Cunninghamia lanceolata) is a very important plantation species that is mainly distributed in Southern China. However, genomic analyses of C. lanceolata have lagged significantly behind those of other conifer species due to a lack of suitable markers. To address this issue, we examined 27,666,670 reads from $C$. lanceolata transcriptome sequences recorded in the SRA database. Assembly produced 35,633 contigs, $1,822(5.11 \%)$ of which contained one or more SSRs. In total, 2,156 SSRs were identified, giving an average SSR density of $68.4 \mathrm{SSR} / \mathrm{Mb}$. The most common SSR types were tri-SSRs $(41.7 \%)$, followed by hexa-(29.8\%), penta$(12.7 \%)$, di-(11.1\%) and tetra-(4.7\%) SSRs. EST-SSR markers based on the 1,822 SSR-containing contigs were developed using the $\mathrm{CMiB}$ pipeline and primer pairs were designed to target 35 loci. Polymorphism was observed in 28 of these loci, for which the number of alleles per locus ranged from 3 to 12 over 16 plus-tree individuals. The observed heterozygosity $(\mathrm{Ho})$, expected heterozygosity $(\mathrm{He})$ and fixation index $\left(F_{\mathrm{IS}}\right)$ values for the targeted loci ranged from 0.125 to $0.938,0.225$ to 0.891 and -0.368 to 0.456 , respectively. The corresponding PIC values ranged from 0.210 to 0.881 , with an average of 0.573 . Some of these markers have since been used in our ongoing genetic diversity analyses of C. lanceolata. To our knowledge, this is the first analysis of SSRs and EST-SSR markers in C. lanceolata, and the identified EST-SSR markers will be useful in future genetic analyses of $C$. lanceolata and related species.
\end{abstract}

Key words: Cunninghamia lanceolata; expressed sequence tag; microsatellite markers; de novo assembly; transcriptome sequences.

\section{Introduction}

The Chinese fir (Cunninghamia lanceolata) is an allogamous, long-lived, evergreen conifer that is mainly distributed in Southern China. It is one of the most important plantation species in this region and is widely used to restore degraded land and as a source of commercial timber in China. However, genetic analyses of this species have lagged behind those of other conifers due to a lack of suitable markers. To date, only a few studies have examined the genetic diversity and phylogeny of $C$. lanceolata and related species, typically by

\footnotetext{
$\left.{ }^{1}\right)$ Central South University of Forestry and Technology, Changsha, Hunan 410004, China.

2) Forestry and Forest Products Research Institute, Tsukuba, Ibaraki 305-8687, Japan.

*) Author for correspondence: YAFENG Wen. E-Mail: wenyafeng7107@163.com
}

analyzing dominant DNA markers using techniques such as RAPD (You and Hong, 1998), ISSR (QI, 2008; YANG et al., 2009) and AFLP (CHUNG et al., 2004). To the authors' knowledge, no microsatellite markers have yet been developed for $C$. lanceolata, which has seriously impeded its genetic analysis and the development of breeding programs.

Genetic studies based on microsatellite markers (also known as simple sequence repeats, or SSRs) have a number of advantages over those based on random fingerprinting approaches (JARNE and LAGODA, 1996; SELKOE and ToONEN, 2006), including the co-dominant inheritance of the markers according to Mendelian laws, their high information content, and their ready detection by PCR amplification. EST-SSR markers offer further advantages over genomic SSRs in that they directly reflect gene expression. However, to develop new species-specific microsatellites, it is necessary to study their flanking sequences using traditional approaches, which is costly and time-consuming (ZANE et al., 2002; SQUIRRELL et al., 2003). With the advent of second generation sequencing technologies, very large amounts of DNA sequence data have been generated and deposited in public databases such as the Sequence Read Archive (SRA), which include high-throughput transcriptome sequences from different taxa. These data are valuable genomic resources that can be used to develop new and specific SSR markers for target species (ZALAPA et al., 2012). In this work, we mined SSRs to develop and characterize a set of EST-SSR markers for C. lanceolata from publically-available transcriptome sequences.

\section{Materials and Methods}

\section{Plant materials}

In order to evaluate the polymorphism of the candidate EST-SSR markers, we selected 16 plus tree individuals from two seed orchards in Southern China. Twelve of these individuals (Y6, Y18, J5, J80, Ht14, Ht16, Jh10, Jh16, Y26, J18, Y110, Y1116) were obtained from the Youxian seed orchard in Hunan province (N27 $18^{\prime}$, $\left.\mathrm{E} 113^{\circ} 47^{\prime}\right)$ and the remaining four were obtained from the Lechang seed orchard in Guangdong province (Lc6, Lc12, Lc18, Lc418) (N25 $\left.{ }^{\circ} 2^{\prime}, \mathrm{E} 113^{\circ} 28^{\prime}\right)$. Leaves from the selected individuals were dried over silica gel and their DNA was extracted using a modification of the CTAB method (Tsumura et al., 1995).

\section{SSR mining and primer design}

Transcriptome sequences for $C$. lanceolata (Accession: SRX151872) were downloaded from the NCBI's SRA 
database (http://www.ncbi.nlm.nih.gov/sra/SRX151872). CLC Genomics Workbench (http://www.clcbio.com) was used to trim and assemble sequence reads, and the recently-developed CMiB pipeline (UENO et al., 2012) was used to mine SSRs and design PCR amplicon primers for contigs that contained SSRs. The CMiB

Table 1. - Basic properties of the 28 polymorhphic EST-SSR markers developed for C. lanceolata.

\begin{tabular}{|c|c|c|c|c|c|}
\hline Locus & Primer scquence $\left(5^{\prime}-3^{\prime}\right)$ & $\begin{array}{l}\text { Repeal } \\
\text { motif }\end{array}$ & $\begin{array}{l}\text { Blaslx lop hil } \\
\text { description }\end{array}$ & $\begin{array}{c}E \\
\text {-value }\end{array}$ & $\begin{array}{l}\text { GenBank } \\
\text { accession no }\end{array}$ \\
\hline contig3078_1424A & $\begin{array}{l}\text { F: GCCTCCCTCGCGCCACAALCAGCCAAGIIGIACAGGC } \\
\text { R: CALACCTIAGCAMGCCICAGC }\end{array}$ & $(\Lambda \mathrm{T})_{8}(\Lambda \mathrm{G})_{18}$ & $\Lambda$ & & $\begin{array}{l}\text { AB } 757708 \\
\mathrm{~B} 757709\end{array}$ \\
\hline contig3400_101A & $\begin{array}{l}\text { F: GCCTCCCTCGCGCCATGAAATTGCGITGTACCGAAGG } \\
\text { R: IAACGAGACGAGCGACAAICICC }\end{array}$ & $(\mathrm{GA})_{13}$ & 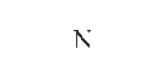 & & $\begin{array}{l}\text { AB } 749554 \\
\text { AB } 749555\end{array}$ \\
\hline contig5354 $691 \mathrm{~A}$ & $\begin{array}{l}\text { F: GCCTCCCTCGCGCCAGATCCTCTGGTACTTGGTGCCC } \\
\text { R: IGCAAAGTCATGICAICICIGGC }\end{array}$ & $(N \mathrm{l})$ & ri & & $\begin{array}{l}\mathrm{A} B 749556 \\
\mathrm{~A}] \mathbf{3} 749557\end{array}$ \\
\hline contig9724_201A & $\begin{array}{l}\text { F: GCCTCCCTCGCGCCAGGTCCGGGCAITIAGAGICATC } \\
\text { R: GCICAGAICCANGGIGACICAGG }\end{array}$ & $(\mathrm{A}[\mathrm{l})$ & N & & $\begin{array}{l}\mathrm{AB} 749560 \\
\mathrm{AB} 749561\end{array}$ \\
\hline contigl $6147-262 \Lambda$ & $\begin{array}{l}\text { F: GCCTCCCTCGCGCCAIGAAIGGACTGCCACAAAIICC } \\
\text { R: TTCTTTGCAGGAAAGCGAACAAG }\end{array}$ & $(\mathrm{AG})_{1}$ & M & & $\begin{array}{l}A B 749550 \\
A B 749551\end{array}$ \\
\hline contigl6322 179A & $\begin{array}{l}\text { I: GCCTCCCTCGCGCCACTGGCATGTAAAGACCATGTTAGG } \\
\text { R: GGCTGAGCCTTTAGTGTATCTTCCC }\end{array}$ & $(\mathrm{IN})$ & $N$ & & $\begin{array}{l}\mathrm{AB} 749552 \\
\mathrm{AB} 749553\end{array}$ \\
\hline contie1997_271B & $\begin{array}{l}\text { E: GCCTTGCCAGCCCGC } A G A M A T G T A C A G G A C C C T G C G \\
\text { R: AAAICAAAGCACACGGIGAGAGC }\end{array}$ & $(\mathrm{IA})_{k}$ & $\Lambda$ & & $\begin{array}{l}\mathrm{AB} 749564 \\
\mathrm{AB} 749565\end{array}$ \\
\hline contig4417 459B & $\begin{array}{l}\text { : GCCTIGCCAGCCCGCAAGAGAAGAGGAGGAGGICCAAG } \\
\text { R: CAGGAGCAGGTGCAGTAGCATTC }\end{array}$ & $\left(\mathrm{AC}(\mathrm{i})_{4}\right.$ & 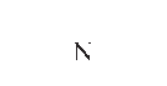 & & $\begin{array}{l}\mathrm{AB} 749570 \\
\mathrm{~A} B 74957]\end{array}$ \\
\hline contig4728_384B & $\begin{array}{l}\text { F: GCCTTGCCAGCCCGCATTATCCGAGGCAGATACGCAC } \\
\text { R: CTTCTCCGTATTTGATCCATCGC }\end{array}$ & $(G G A)_{10}$ & Ri & & $\begin{array}{l}\mathrm{AB} 749572 \\
\mathrm{AB} 749573\end{array}$ \\
\hline contig76 $76 \quad 683 \mathrm{~B}$ & $\begin{array}{l}\text { F: GCCTTGCCAGCCCGCGAGCCGTGAMA } \\
\text { R: } \triangle C \text { COTCGGATTGTCTCAGANACG }\end{array}$ & $(G \wedge A)_{12}$ & $N$ & & $\mathrm{AB} 749574$ \\
\hline contig767I_1267B & $\begin{array}{l}\text { F: GCCTTGCCAGCCCGCTG } A T C T T G G C A T G T C A G T C T G G \\
\text { R: TGTCTGTCTGCCTGC }\end{array}$ & $(\Lambda T)_{0}$ & $N$ & & $\begin{array}{l}A B 749576 \\
A B 749577\end{array}$ \\
\hline contig20158_829B & $\begin{array}{l}\text { F: GCCTTGCCAGCCCGCTCCACACCTTGCTGCTCTCTTC } \\
\text { R: GAGATTAGGGCACTAGCGATGGG }\end{array}$ & $(\mathrm{AT})_{4}$ & $N$ & & $\begin{array}{l}A B 749566 \\
A B 749567\end{array}$ \\
\hline contig25400 $116 \mathrm{~B}$ & $\begin{array}{l}\text { F: GCCTTGCCAGCCGGCAGCGATTAGAATCOGAGCAGAG } \\
\text { R: GCICGAGNICIGCGLAGGAMGIG }\end{array}$ & (ATC) & $\begin{array}{c}\text { Hypothetical } \\
\text { protejn } \\
\text { (Fowering } \\
\text { promoting } \\
\text { factor l) }\end{array}$ & $3.1 \mathrm{E}-13$ & $\begin{array}{l}\mathrm{AB} 749568 \\
\mathrm{AB} 749569\end{array}$ \\
\hline contig2573_171C & $\begin{array}{l}\text { I: AGGACCAGGCTACCGTGAAIGCGACI'IGCANAIICIGG } \\
\text { R: CGALTCCTCAATCACTTGGCTG }\end{array}$ & $(\Lambda G \Lambda)_{10}$ & $N$ & & $\begin{array}{l}A B 749582 \\
\mathrm{AB} 749583\end{array}$ \\
\hline contig6064 15630 & $\begin{array}{l}\text { F: GGACCAGGCTACCGTGCACAGTCATGTCCGTTATCGTTC } \\
\text { R: АATGGC AGCAACATCAGAANTGG }\end{array}$ & $(\mathrm{IA})$ & ri & & $\begin{array}{l}\mathrm{B} 749586 \\
\mathrm{AB} 749587\end{array}$ \\
\hline contig6319 250C & $\begin{array}{l}\text { F: CAGGACCAGGCTACCGTGGCGGCCATTTATATCATCTTC } \\
\text { R: CACGCCIGIAAI"ICATCICGGIC }\end{array}$ & $(\mathrm{C} / \mathrm{N})_{\mathrm{O}}$ & $N$ & & $\begin{array}{l}\text { AD } 749588 \\
\text { A] } 749589\end{array}$ \\
\hline contigl2886_2058C & $\begin{array}{l}\text { I: CAGGACCAGGCTACCGTGGGAGCCCIJAGAG ITACGGAG } \\
\text { R: TGGGCTCCATTCATTTGTACTGC }\end{array}$ & $(\mathrm{ATA})_{3}$ & $N$ & & $\begin{array}{l}A] 3749578 \\
A B 749579\end{array}$ \\
\hline contig16181 $1285 \mathrm{C}$ & $\begin{array}{l}\text { F: AGGACCAGGCTACCGTGGGTACTGCG MATTTCAMATCC } \\
\text { R: TGTTCAAG МА }\end{array}$ & $\left(\mathrm{IC}_{y}\right.$ & $x$ & & $\begin{array}{l}\triangle B 749580 \\
A B 74958]\end{array}$ \\
\hline contig476 $526 \mathrm{D}$ & $\begin{array}{l}\text { F: GGAGAGCCGAGAGGTGTTTGGGACCTTATGGAG } \\
\text { R: AAACCACCAGGTTGAGAAGCAGC }\end{array}$ & $(\mathrm{GGM})$ & Ni & & $\begin{array}{l}\text { AB } 749602 \\
\text { AT } 749603\end{array}$ \\
\hline contig1560_1789D & $\begin{array}{l}\text { F: GGAGAGCCGAGAGGTGTTTCGGCTCTCCGACTCCTTAAC } \\
\text { R: AGAATCGCGTCCAGAACACAGAG }\end{array}$ & $(\mathrm{CT})_{11}$ & $N$ & & $\begin{array}{l}\text { AD7 } 79594 \\
\text { AB } 749595\end{array}$ \\
\hline contig4056_974D & $\begin{array}{l}\text { F: GAGAGCCGAGAGGTG]CCAGGAGTCIGIGANICCGAAG } \\
\text { R: CAGTACCANTTCACCCAGCAGC }\end{array}$ & $(\mathrm{CTG})$ & $N$ & & $\begin{array}{l}\text { AB } 749600 \\
\text { AB } 749601\end{array}$ \\
\hline contig $10192 \_16770$ & $\begin{array}{l}\text { F: GAGAGCCGAGAGGTG]CAAGAAGTICGGCCATIGAGAG } \\
\text { R: CCCATGAGGALICAGAACAIGC }\end{array}$ & $(C \mathrm{CT})_{\| i r}$ & $N$ & & $\begin{array}{l}A B 749590 \\
A B 749591\end{array}$ \\
\hline contidit4033_236D & 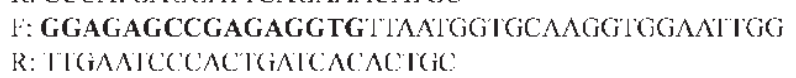 & $(G] \wedge \wedge)_{10}$ & $N$ & & $\begin{array}{l}\text { AB749592 } \\
\text { A13749593 }\end{array}$ \\
\hline contigl6781 9130 & 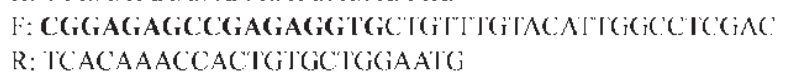 & $(\mathrm{CTC})$ & Ni & & $\begin{array}{l}\text { A13749596 } \\
\text { A]1749597 }\end{array}$ \\
\hline contig18815_185D & $\begin{array}{l}\text { F: CGGAGAGCGGAGAGGTGGTTGGGATGTCATGAAGATTGG } \\
\text { R: TGA A }\end{array}$ & $\left(\mathrm{CC}_{\mathrm{Cl}}\right.$ & $N$ & & $\begin{array}{l}\text { AB749598 } \\
A B 749599\end{array}$ \\
\hline
\end{tabular}

Note: N No hits found; 4 universal primers sequence (5'-3') and their PCR fluorophore:

Tail A (FAM), GCCTCCCTCGCGCCA; Tail B (HEX), GCCTTGCCAGCCCGC;

Tail C (NED), CAGGACCAGGCTACCGTG; Tail D (PET), CGGAGAGCCGAGAGGTG. 
pipeline is based on a combination of the CD-HIT-EST, MISA, ipcress and BlastCLUST packages, and produces non-redundant SSR sequences along with corresponding primer pairs. 35 di- and tri-nucleotide microsatellite loci containing SSRs with nine or more repeats each were selected for further evaluation.

\section{PCR amplification and polymorphism testing}

Genotyping was performed using fluorescently labelled universal primers and a three-primer PCR approach (BLACKET et al., 2012). Each locus-specific forward primer was modified with a 5 ' universal primer sequence tail (A, B, C or D; see Table 1). The primer pairs were then tested against DNA from two sampled individuals to verify that they afforded successful amplification. PCR was performed according to the protocol supplied with the QIAGEN ${ }^{\circledR}$ Multiplex PCR kit, in a $10.0 \mu \mathrm{L}$ reaction volume containing $1 \times$ Multiplex PCR master mix (Qiagen), $1 \mu \mathrm{L}$ of $10 \times$ primer mix, and 5-10 ng of template DNA. The $10 \times$ Primer mix for each marker in the multiplex contained $1.0 \mu \mathrm{M}$ universal fluorescent primer, $1.0 \mu \mathrm{M}$ tailed forward primer and $2.0 \mu \mathrm{M}$ reverse primer. The PCR amplification conditions were: $15 \mathrm{~min}$ at $95^{\circ} \mathrm{C}$, then 35 cycles of $30 \mathrm{~s}$ at $94^{\circ} \mathrm{C}, 90 \mathrm{~s}$ at $60^{\circ} \mathrm{C}$, and $60 \mathrm{~s}$ at $72^{\circ} \mathrm{C}$, followed by a 30 min extension step at $60^{\circ} \mathrm{C}$. The PCR products were electrophoretically separated on $2 \%$ agarose gels stained with ethidium bromide. For loci that were successfully amplified, singleplex PCR amplification was performed to investigate their polymorphism in the 16 sampled individuals. The PCR amplification system and conditions used in this second round of amplifications were the same as those described above. Four fluorescently labelled markers with different universal primers (A, B, $\mathrm{C}$ or $\mathrm{D})$ were pooled in a single lane for allele screening and analyzed with an ABI3100 genetic analyzer using the Liz 600 size standards. GENALEX6.3 (PEAKALL and SMouse, 2006) was used to estimate a range of genetic parameters for each locus, including the number of alleles per locus $(\mathrm{Na})$, observed heterozygosity $(\mathrm{Ho})$, expected heterozygosity $(H e)$, and fixation index $\left(F_{\text {IS }}\right)$. The polymorphism information content (PIC) (BoTSTEIN et al., 1980) was determined for each locus using MS-tools (PARK, 2001). Exact tests of Hardy-Weinberg equilibrium $(H W E)$ and Linkage disequilibrium $(L D)$ were assessed using version 4.2 of the on-line GENEPOP tool (RAYMOND and RousseT, 1995; http://genepop.curtin.edu.au/ index.html). Null alleles were detected using Microchecker 2.2.3 (VAN OOSTERHOUT et al., 2004). In order to identify putative functions for SSR-containing contigs, they were blasted against the NCBI NR protein database using Blast2GO (ConESA et al., 2005) with an evalue cutoff of $1 \mathrm{e}-3$.

\section{Results and Discussion}

\section{SSRs mining of EST contigs}

We examined $27,666,670$ reads of $C$. lanceolata derived from transcriptome sequences. Assembly generated 35,633 contigs, of which 1,822 (5.11\%) contained one or more SSRs. In total, 2,156 SSRs were identified with threshold repeat numbers of $6,5,4,3$ and 3 for di-, tri-, tetra-, penta- and hexa-SSRs, respectively. The average SSR density was 68.4 SSRs/Mb, which is much lower than that observed in Cryptomeria japonica (UENO et al., 2012), but higher than the values for loblolly pine and spruce (BÉRUBÉ et al., 2006). Tri-SSRs were the most common SSR type encountered $(41.7 \%)$, followed by hexa-(29.8\%), penta-(12.7\%), di-(11.1\%) and tetra(4.7\%) SSRs. The most common tri-SSR motif was AAG, which was found in $239(26.6 \%)$ of all tri-SSRs. The most common di-SSR motifs were AG and AT, both of which occurred 109 times (45.6\% of all di-SSRs). With the advent of high-throughput sequencing technologies, several computational tools or pipelines have been developed for SSR mining, including TROLL (CASTELO et al., 2002), MISA (THIEL et al., 2003), CMiB (UENO et al., 2012) and ESMP (SARMAH et al., 2012). CMiB is a new method developed in our laboratories that emphasizes the identification of unique primer pairs targeting specific genes and relies on a combination of widely-used programs. It has previously been successfully used to mine SSRs for Cryptomeria japonica.

\section{Characterization of selected EST-SSR markers}

Of the 35 primer pairs designed, $29(82.9 \%)$ produced clear PCR fragment patterns with one or two bands, one produced multiple (more than two) bands, and 5 (14.3\%) did not produce any fragments. Polymorphic genotypes were obtained for 28 loci (Table 1 and Table 2) with the number of alleles per locus ranging from 3 to 12 for the 16 studied individuals. The observed heterozygosity $(\mathrm{Ho})$, expected heterozygosity $(\mathrm{He})$ and fixation index $\left(F_{\text {IS }}\right)$ values for each locus ranged from 0.125 to 0.938 , 0.225 to 0.891 and -0.368 to 0.456 , respectively. Two loci (contig4417_459B and contig16147_262A) showed significant deviation from Hardy-Weinberg equilibrium $(H W E)$ due to heterozygote deficiency or null alleles. The PIC values for the loci ranged from 0.210 to 0.881 , with an average of 0.573 . These values indicate that the identified EST-SSR markers exhibit a high degree of polymorphism. Significant linkage disequilibrium was observed for eleven of the 378 possible pairs of the 28 EST-SSR markers $(p<0.05)$. Possible null alleles were identified in two loci (contig4417_459B and contig3078_1424A), with null allele frequencies of 0.22 and 0.11 , respectively.

In order to assess the power of these markers, Principal Coordinates Analysis (PCA) was performed using GENALEX6.3. The four individuals from the Lechang seed orchard formed a small cluster based on the PCA results (data not shown), indicating that they were closely genetically related, while the 12 individuals from the Youxian seed orchard formed looser clusters because they were collected over a broader range in Hunan Province. Since their identification, some of the markers developed in this work have been used in our ongoing analysis of genetic diversity in C. lanceolata. To our knowledge, the results presented herein represent the first analysis of SSRs and EST-SSR markers in C. lanceolata. The newly-established EST-SSR markers will be very useful in future genetic analyses of $C$. lanceolata and closely related species. 
Table 2. - 28 Polymorphic EST-SSR markers of C. lanceolata screening in 16 individuals.

\begin{tabular}{|c|c|c|c|c|c|c|c|c|}
\hline Locus & $\mathbf{N}$ & $\begin{array}{c}\text { Size } \\
\text { Rang(bp) }\end{array}$ & $\mathrm{Na}$ & Ho & $H e$ & $F_{\mathrm{IS}}$ & PIC & $\begin{array}{l}\text { Null allcles } \\
\text { (frequency) }\end{array}$ \\
\hline contig $3078 \quad 1424 \mathrm{~A}$ & 16 & $343-375$ & 12 & 0,688 & 0.883 & 0.221 & 0.872 & Yes $(0.11)$ \\
\hline contig3400_101A & 16 & $273-297$ & 10 & 0.875 & 0.861 & -0.016 & 0.846 & No \\
\hline contig5354_691A & 15 & $186-190$ & 3 & 0.400 & 0.384 & -0.040 & 0.351 & No \\
\hline contig $5410 \_1886 \Lambda$ & 16 & $229-233$ & 3 & 0.625 & 0.635 & 0.015 & 0.557 & No \\
\hline contig9724_201A & 16 & $211-241$ & 10 & 0.813 & 0.846 & 0.034 & 0.824 & No \\
\hline contigl6147-262A & 16 & $288-298$ & 5 & 0.500 & 0.668 & $0.251^{\circ}$ & 0.623 & No \\
\hline contigl6322_179 & 16 & $282-290$ & 4 & 0.563 & 0.637 & 0.117 & 0.587 & No \\
\hline contig1382_349B & 16 & $258-279$ & 6 & 0.625 & 0.648 & 0.036 & 0.607 & No \\
\hline contig1997_271B & 16 & $247-255$ & 5 & 0.813 & 0.594 & -0.368 & 0.535 & No \\
\hline contig4417_459B & 16 & $269-283$ & 5 & 0.375 & 0.689 & $0.456^{k+}$ & 0.646 & Yes $(0.22)$ \\
\hline conlig4 $428 \quad 38413$ & 15 & $336-354$ & 6 & 0.400 & 0.444 & 0.100 & 0.425 & No \\
\hline contig7616 68313 & 16 & $260-281$ & 7 & 0.688 & 0.785 & 0.124 & 0.752 & No \\
\hline contig $7671 \quad 1267 \mathrm{~B}$ & 16 & $144-158$ & 5 & 0.563 & 0.664 & 0.153 & 0.607 & No \\
\hline contig20158 $829 \mathrm{~B}$ & 16 & $324-344$ & 9 & 0.813 & 0.795 & -0.022 & 0.774 & No \\
\hline contig25400 $116 \mathrm{~B}$ & 16 & $337-349$ & 5 & 0.750 & 0.713 & -0.052 & 0.660 & No \\
\hline contig406_1200C & 16 & $348-384$ & 11 & 0.813 & 0.869 & 0.065 & 0.855 & No \\
\hline conlig2573_171C & 16 & $240-258$ & 4 & 0.438 & 0.416 & -0.052 & 0.392 & No \\
\hline contig6064 $1563 \mathrm{C}$ & 16 & $357-363$ & 4 & 0.688 & 0.664 & -0.035 & 0.616 & No \\
\hline contig6319 $250 \mathrm{C}$ & 16 & $126-135$ & 4 & 0.563 & 0.609 & 0.077 & 0.530 & No \\
\hline contig12886 $2058 \mathrm{C}$ & 16 & $231-240$ & 3 & 0.563 & 0.506 & -0.112 & 0.406 & No \\
\hline contigl6181 $1285 \mathrm{C}$ & 16 & $293-297$ & 3 & 0.375 & 0.490 & 0.235 & 0.397 & No \\
\hline contig476 $526 \mathrm{D}$ & 16 & $153-159$ & 3 & 0.313 & 0.275 & -0.135 & 0.257 & No \\
\hline contig1560_1789D) & 16 & $129-147$ & 5 & 0.438 & 0.492 & 0.111 & 0.458 & No \\
\hline conlig $4056 \_974 \mathrm{D}$ & 16 & $223-238$ & 3 & 0.125 & 0.225 & 0.443 & 0.210 & No \\
\hline contig10192_1677D & 16 & $354-375$ & 6 & 0.750 & 0.750 & 0.000 & 0.717 & No \\
\hline contig14033 236D & 16 & $280-286$ & 3 & 0.250 & 0.271 & 0.079 & 0.248 & No \\
\hline contig167819135) & 16 & $136-148$ & 4 & 0.500 & 0.416 & -0.202 & 0.392 & No \\
\hline contigl8815 1850 & 16 & $226-270$ & 12 & 0.938 & 0.891 & -0.053 & 0.881 & No \\
\hline
\end{tabular}

Note: $\mathrm{N}$ number of individuals genotyped; $\mathrm{Na}$ number of alleles per locus detected; $\mathrm{Ho}$ observed heterozygosity; $H e$ expected heterozygosity; $F_{\text {IS }}$ fixation index; *** significant departure from Hardy-Weinberg equilibrium (HWE) $(P<0.05, P<0.001$, respectively); PIC polymorphism information content.

List of 11 significant linkage disequilibrium pairs markers $(P<0.05)$

contig1997_271B and contig2573_171C, contig1997_271B and contig5354_691A,

contig4056_974D and contig5354_691A, contig476_526D and contig5410_1886A,

contig2573_171C and contig12886_2058C, contig4417_459B and contig16181_1285C,

contig7671_1267B and contig16147-262A, contig18815_185D and contig16147-262A,

contig1560_1789D and contig20158_829B, contig5410_1886A and contig20158_829B, contig4417_459B and contig16781_913D.

\section{Acknowledgements}

This research was supported by National Natural Science Foundation of China (30972357), the Hunan Provincial Natural Science Foundation of China (10JJ2018), and by a Grant-in-Aid for JSPS Fellows (11F00787).

\section{Reference}

BÉRubé, Y., J. Zhuang, D. Rungis, S. RALPH, J. BohlmanN and K. RITLAND (2007): Characterization of EST-SSRs in loblolly pine and spruce. Tree Genetics \& Genomes 3: 251-259. 
Blacket, M. J., C. Robin, R. T. Good, S. F. Lee and A. D. MiLler (2012): Universal primers for fluorescent labelling of PCR fragments - an efficient and cost-effective approach to genotyping by fluorescence. Molecular Ecology Resources 12: 456-463.

Botstein, D., R. L. White, M. Skolnick and R. W. Davis (1980): Construction of a genetic linkage map in man using restriction fragment length polymorphism. Am J Hum Genet 32: 314-331.

Castelo, A. T., W. Martins and G. R. Gao (U2002): Trolltandem repeat occurrence locator. Bioinformatics Applications Note 18: 634-636.

Chung, J. D., T. P. Lin, Y. C. Tan, M. Y. Lin, S. Y. Hwang (2004): Genetic diversity and biogeography of Cunninghamia konishii (Cupressaceae), an island species in Taiwan: a comparison with Cunninghamia lanceolata, a mainland species in China. Molecular Phylogenetics and Evolution 33: 792-801.

Conesa, A., S. Gotz, J. M. Garcia-Gomez, J. Terol, M. TALON and M. ROBLES (2005): Blast2GO: a universal tool for annotation, visualization and analysis in functional genomics research. Bioinformatics 21 : 3674-3676.

JARNE, P and P. J. LAGODA (1996): Microsatellites, from molecules to populations and back. Trends in Ecology and Evolution 11: 424-429.

PARK, S. D. E. (2001): Trypanotolerance in West African cattle and the population genetic effects of election [Ph.D. thesis]. University of Dublin.

Peakall, R. and P. E. Smouse (2006): GENALEX 6 : Genetic analysis in Excel. Population genetic software for teaching and research. Molecular Ecology Notes 6: 288-295.

QI, M. (2008): Genetic diversity of wide cross population of Cunninghamia lanceolata and platycladu orientalis. Bulletin of botanical research 28: 299-303.

Sarmah, R., J. Sahu, B. Dehury, K. Sarma, S. Sahoo, M. Sahu, M. Barooah, P. Sen and M. K. Modi (2012): ESMP: A high-throughput computational pipeline for mining SSR markers from ESTs. Bioinformation 8: 206-208.

RAYMond, M. and F. Rousset (1995): Genepop (Version1.2): Population genetics software for exact tests and ecumenicism. Journal of Heredity 86: 248-249.
Selkoe, K. A. and R. J. Toonen (2006): Microsatellites for ecologists: a practical guide to using and evaluating microsatellite markers. Ecology Letters 9: 615-629.

SquirRell, J., P. M. Hollongsworth, M. WoOdHeAd, J. Russell, A. J. Lowe, M. GiBBY and W. Powell (2003): How much effort is required to isolate nuclear microsatellites from plants? Molecular Ecology 12: 1339-1348.

Thiel, T., W. Michalek, R. K. Varshney and A. Graner (2003): Exploiting EST databases for the development and characterization of gene-derived SSR-markers in barley (Hordeum vulgare L.). Theor Appl Genet 106: 411-422.

Tsumura, Y., K. Yoshimura, N. Tomaru and K. OHBA (1995): Molecular phylogeny of conifers using RFLP analysis of PCR-amplified specific chloroplast genes. Theoretical and Applied Geneticst 91: 1222-1236.

Ueno, S., Y. Moriguchi, K. Uchiyama, T. U. Ihara, N. Futamura, T. SAKurai, K. Shinohara and Y. TsumuRA (2012): A second generation framework for the analysis of microsatellites in expressed sequence tags and the development of EST-SSR markers for a conifer, Cryptomeria japonica. BMC Genomics 13: 136.

Van Oosterhout, C., W. F. Hutchinson, D. P. M. Wills and P. SHIPLEY (2004): MICRO CHECKER: software for identifying and correcting genotyping errors in microsatellite data. Molecular Ecology Notes 4: 535-538.

YANG, Y. L., X. Q. MA and M. Q. Z. (2009): Molecular polymorphic analysis for different geographic provenances of Chinese fir. Journal of Tropical and Subtropical Botany 17: 183-189.

You, Y. and J. S. HoNG (1998): Application of RAPD marker of genetic variation of Chinese fir provenances. Scientia Silvae Sinicae 34: 33-38.

Zalapa, J. E., H. Cuevas, H. Zhu, S. Steffan, D. Senalik, E. ZELDIN and B. MCCown et al. (2012): Using next-generation sequencing approaches for the isolation of simple sequence repeat (SSR) loci in the plant sciences. American Journal of Botany 99: 193-208.

ZANE, L., L. BARgELlONI and T. PATARNELlo (2002): Strategies for microsatellite isolation: A review. Molecular Ecology 11: 1-16. 